CZASOPISMO INŻYNIERII LA¿DOWEJ, ŚRODOWISKA I ARCHITEKTURY JOURNAL OF CIVIL ENGINEERING, ENVIRONMENT AND ARCHITECTURE

JCEEA, t. XXXIII, z. 63 (1/I/16), styczeń-marzec 2016, s. 381-388

\author{
Damian BĘBEN ${ }^{1}$ \\ Wojciech ANIGACZ ${ }^{2}$ \\ Jacek KWIATKOWSKI ${ }^{3}$
}

\title{
OCENA PRZYDATNOŚCI GEODEZYJNYCH METOD POMIAROWYCH DO BADAŃ PRZEMIESZCZEŃ MOSTU WISZĄCEGO
}

\begin{abstract}
Celem badań było porównanie możliwości i ocena przydatności trzech metod pomiarowych, tj. tachimetryczną, fotogrametryczną i skaningu laserowego wykorzystanych do ustalenia zmian geometrycznych konstrukcji. Metody przetestowano na wiszącym moście technologicznym o rozpiętości głównego przęsła $165 \mathrm{~m}$. Informacje o zmianie kształtu konstrukcji mostu pod wpływem obciążenie użytkowego są bardzo istotne ze względów utrzymaniowych (eksploatacyjnych). Zakres badań obejmował wykonanie pomiarów zmian strzałki ugięcia mostu w trakcie pracy taśmociągu i jego postoju. Pomiary tachimetryczne wykonano precyzyjnym tachimetrem firmy Leica TC2002. W metodzie fotogrametrycznej dla uzyskania wysokich rozdzielczości lustrzankę Canon 650D osadzono w obrotnicy GigaPano. $\mathrm{W}$ przypadku skaningu laserowego skorzystano z skanera FARO Focus 3D X130.W wyniku przeprowadzenia badań doświadczalnych uzyskano przemieszczenia głównego przęsła mostu nie przekraczające wielkości $72 \mathrm{~mm}$, które są mniejsze od dopuszczalnych obliczonych zgodnie z normą mostową. Analiza uzyskanych wyników ze skanowania laserowego nie pozwoliły na oszacowanie uzyskanych przemieszczeń ze względu na zbyt dużą odległość skanera od mostu i zbyt małą gęstość skanów.
\end{abstract}

Słowa kluczowe: most, pomiary, skaning laserowy, fotogrametria, tachimetria

\section{Wstęp}

Zazwyczaj badania dynamiczne i statyczne wykonywane sa na mostach w celu potwierdzenia założeń projektowych lub jako badania diagnostyczne w celu zapewnienia prawidłowego utrzymania. Typowe badania są zwykle przeprowadzane przy użyciu akcelerometrów, czujników tensometrycznych, induk-

\footnotetext{
${ }^{1}$ Autor do korespondencji/corresponding author: Damian Bęben, Wydział Budownictwa i Architektury Politechnika Opolska, ul. Katowicka 48, 45-061 Opole, 77449 8581, d.beben@po.opole.pl

${ }^{2}$ Wojciech Anigacz, Wydział Budownictwa i Architektury Politechnika Opolska, ul. Katowicka 48, 45-061 Opole, 77449 8581, w.anigacz@ po.opole.pl

${ }^{3}$ Jacek Kwiatkowski, J\&L Consulting, Obr. Stalingradu 29, 45-594 Opole, info@jl-consulting.pl
} 
cyjnych i zegarowych. Większość z tych czujników wymaga bezpośredniego kontaktu z konstrukcją, co w pewnych warunkach może stwarzać problemy z dostępnością do obiektu badań i często wymaga użycia rusztowań. W pracach [1-4] badania konstrukcji przeprowadzano w sposób klasyczny, tj.: zakładano osnowę pomiarową referencyjną poza badanym obiektem, a na samym obiekcie oznaczano punkty pomiarowe. Takie podejście jest poprawne w przypadku prowadzenia badań w dłuższym okresie czasu. Punkty referencyjne poza badanym obiektem pozwalają na określenie zmian geometrii konstrukcji mostu w bezwzględnym układzie odniesienia jakim są punkty referencyjne. W przedstawianym przypadku chciano do minimum ograniczyć prace przygotowawcze. Jako punkty pomiarowe postanowiono wykorzystać dobrze widoczne detale konstrukcji mostu.

W tym artykule postanowiono poddać analizie trzy metody pomiarowe (tachimetryczna, skaningu laserowego i fotogrametryczna) służące do bezdotykowego pomiaru przemieszczeń mostu. Szybko rozwijające się techniki pomiarowe, zwłaszcza geodezyjne, a w szczególności pomiary masowe umożliwiają praktycznie uzyskanie pełnej informacji o obiekcie i zmianach jego geometrii [4].

\section{Opis mostu}

Badany obiekt to dwupylonowy stalowy most wiszący położony nad rzeką Odrą służący do przejścia ciągiem transportowym z kopalni margla „Forlwark” do cementowni Górażdże (rys. 1).Most składa się z pięciu przęseł - czterech skrajnych zalewowych oraz przęsła nurtowego. Konstrukcja galerii transportowej podwieszona jest za pomocą wieszaków do głównych lin nośnych rozmieszczonych nad dwiema parami słupów (pylonów).

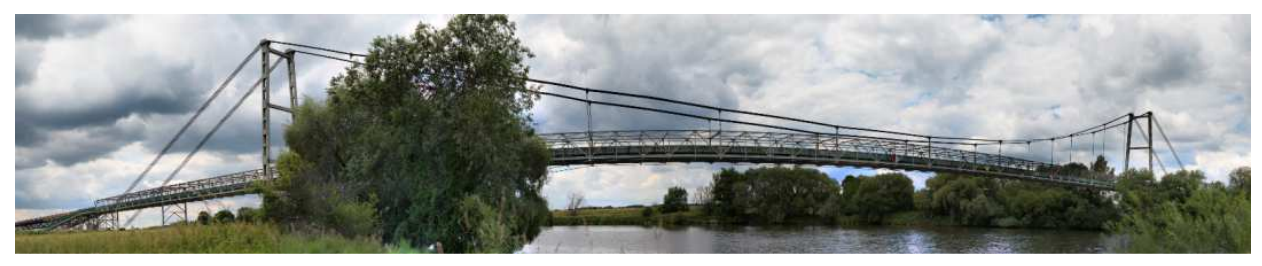

Rys. 1. Widok mostu od strony wody górnej

Fig. 1. View of the bridge from the upper water side

Zasadniczym elementem konstrukcyjnym obiektu jest przęsło nurtowe zawieszone na linach o rozpiętości w świetle osi pylonów 165,00 m. Całkowita długość obiektu wynosi 285,00 m. Most został zaprojektowany jako ustrój wiszący na dwóch stalowych pylonach, przez które przechodzi układ $2 \times 6$ lin nośnych o średnicy $48 \mathrm{~mm}$. Bezpośrednio na podłużnicach ułożona jest płyta ortotropowa. Pylony o wysokości $26,5 \mathrm{~m}$ opierają się za pośrednictwem przegubowych łożysk stalowych na żelbetowych fundamentach. Liny połączone są z py- 
lonem w sposób stały za pośrednictwem głowicy i złącz śrubowych, które umożliwiają przesuwanie lin na wierzchołku pylonu. Most przeznaczony jest do transportu urobku wapienia za pomocą taśmociągu umieszczonego $\mathrm{w}$ galerii transportowej. Masa transportowanego urobku przez most to $900-1100 \mathrm{Mg} / \mathrm{h}$, a prędkość poruszania taśmociągu wynosi $2 \mathrm{~m} / \mathrm{s}$.

\section{Metodologia badawcza}

Jednym z najistotniejszych czynników wpływających na wybór metody jest specyfika geometryczna mostu. W analizowanym przypadku jest to obiekt liniowy, którego przęsło ma długość $165 \mathrm{~m}$. Rozpiętość mostu jest o tyle istotna, że dokładność wyznaczenia położenia punktu pomiarowego zmniejsza się wraz z odległością, co musi być uwzględniane w tego typu pomiarach. Badania przeprowadzono po czterdziestu latach eksploatacji tego mostu. Przemieszczenia mostu zarejestrowano podczas normalnej pracy w sposób ciągły przez 12 godziny. W oparciu o te metody ustalono przemieszczenia przęsła nurtowego.

\subsection{Metoda tachimetryczna}

Metoda tachimetryczna polega na wyznaczeniu w terenie przestrzennych współrzędnych biegunowych, tj.: odległości oraz kątów pionowych i poziomych od zadanych kierunków nawiązania. Dostępne są tachimetry, teoretycznie mierzące $\mathrm{w}$ warunkach laboratoryjnych odległość $\mathrm{z}$ dokładnością $1 \mathrm{~mm}$ i kierunki z dokładnością 0,5 ". W warunkach terenowych uzyskiwane dokładności są na ogół znacznie mniejsze i oscylują w granicach 1-5 mm dla odległości i 3-10" dla wyznaczenia kierunków. Rozdzielczość kątowa instrumentu pomiarowego ma duże znaczenie zwłaszcza dla identyfikacji detali np. krawędzi przy dużych odległościach $[1,5]$. W analizowanym przypadku, stanowiska tachimetru usytuowano z dwóch stron rzeki w celu zmniejszenia długości celowych to jest odległości pomiędzy stanowiskiem tachimetru a punktem pomiarowym.

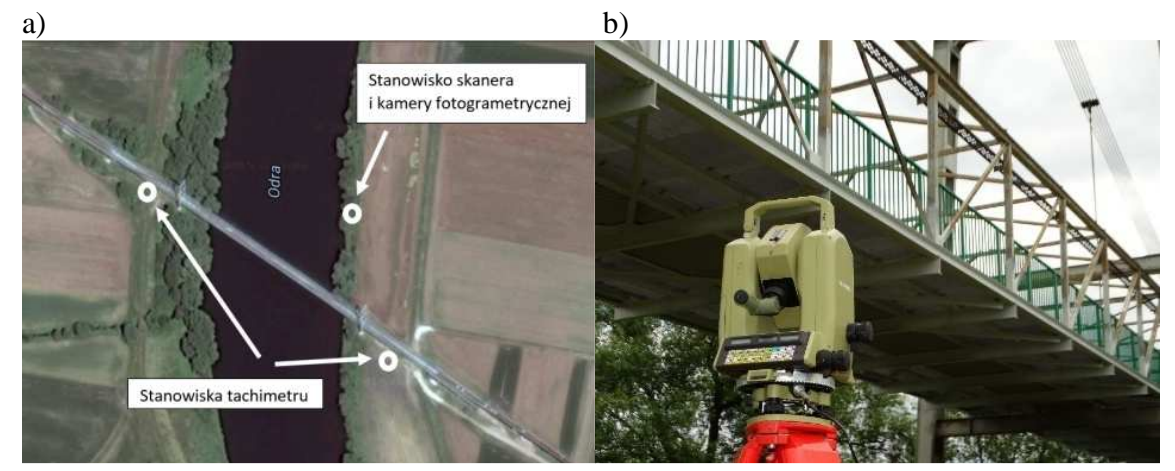

Rys. 2. Usytuowanie stanowisk pomiarowych tachimetru, skanera i kamery fotogrametrycznej

Fig. 2. Placement of measurement stations for tachymeter, scanner and photogrammetric camera 


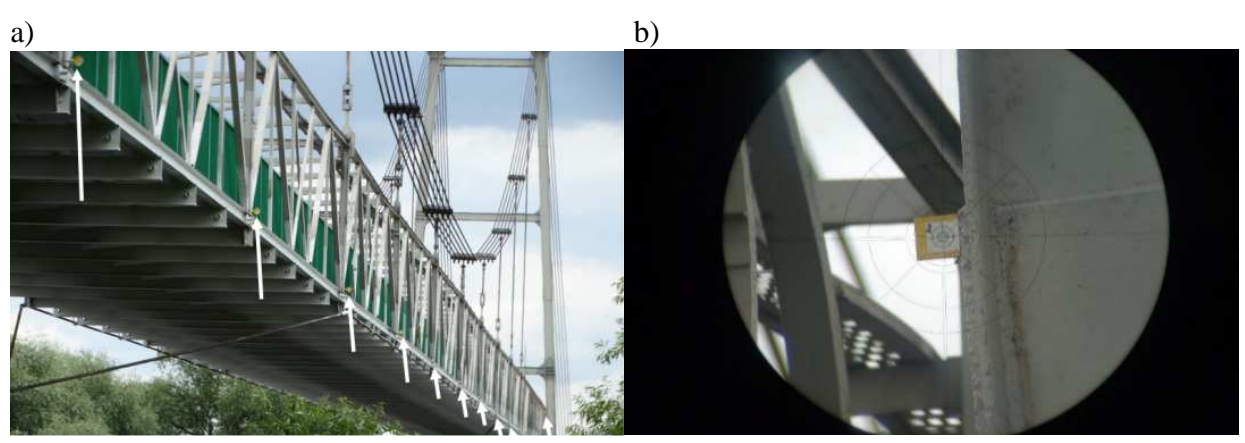

Rys. 3. Badany most z użyciem tachimetru: a) rozmieszczenie tarcz pomiarowych na galerii transportowej, b) widok tarczy pomiarowej przez lunetę tachimetru

Fig. 3. The bridge during testing with using tachymeter: a) distribution of the measurement targets on the transport gallery, b) view of the measurement target through the tachymeter's telescope

W przedstawianym przypadku odległość ta nie przekraczała $100 \mathrm{~m}$ (rys. 2). Cechą charakterystyczną tej metody jest dyskretność pomiaru. Do badań wykorzystano totalstation TC2002 firmy Leica(rys. 2b) oraz kilkanaście dwustronnych tarcz dalmierczych (rys. 3). Tarcze pomiarowe usytuowano w punktach węzłowych galerii transportowej nad poprzecznicami mostu (rys. 3a). Wyniki przemieszczeń uzyskane tą metodą przyjęto jako dane referencyjne dla pozostałych metod. Poprawność otrzymanych rezultatów przemieszczeń zweryfikowano pomiarem $\mathrm{z}$ drugiego stanowiska. Obraz widziany przez lunetę tachimetru pokazano na rys. 3b. Otwór w środku tarczy ma średnicę $5 \mathrm{~mm}$. Na tej podstawie można wnioskować, że dokładność celowania (pomiaru kierunku) była rzędu 1-2 mm.

\subsection{Metoda fotogrametryczna}

W opisywanym przypadku autorzy do wykonania zdjęć wykorzystali aparat fotograficzny Canon 650D z obiektywem o stałej ogniskowej wynoszącej $85 \mathrm{~mm}$ i obrotnicy GigaPano(rys. 4).Potwierdzony w laboratorium na testowym prostokącie poziom aberracji sferycznych nie przekraczał 3 kolumn pikseli matrycy. Do złożenia (stitching) zdjęć użyto oprogramowania Kolor AutoPano Giga 4.0. Do skalibrowania wygenerowanej panoramy poprzez przeskalowanie definiujące „rozmiar” pojedynczego piksela wykorzystano z programu komputerowego Photoshop CC. Do wyskalowania panoramy mostu do zadanego rozmiaru piksela wykorzystano z dystansów charakterystycznych, jakimi w badanym przypadku były odległości pomiędzy kolejnymi segmentami przęsła (rys. 3a). Zaletą metody fotogrametrycznej jest między innymi: krótki czas pomiaru, możliwość wizualizacji z elementami uprzestrzennienia i możliwość wielokrotnej interpretacji pomiaru. Finalne dane analityczne ilustrujące efekt sesji pomiarowej zależą od trzech czynników: (i) rozdzielczości matrycy aparatu cyfrowego, (ii) jakości optyki, (rozdzielczości, redukcji aberracji sferycznych), (iii) umiejętności oceny przez oprogramowanie procesu interakcji z użytkownikiem, np. przy stichingu. 


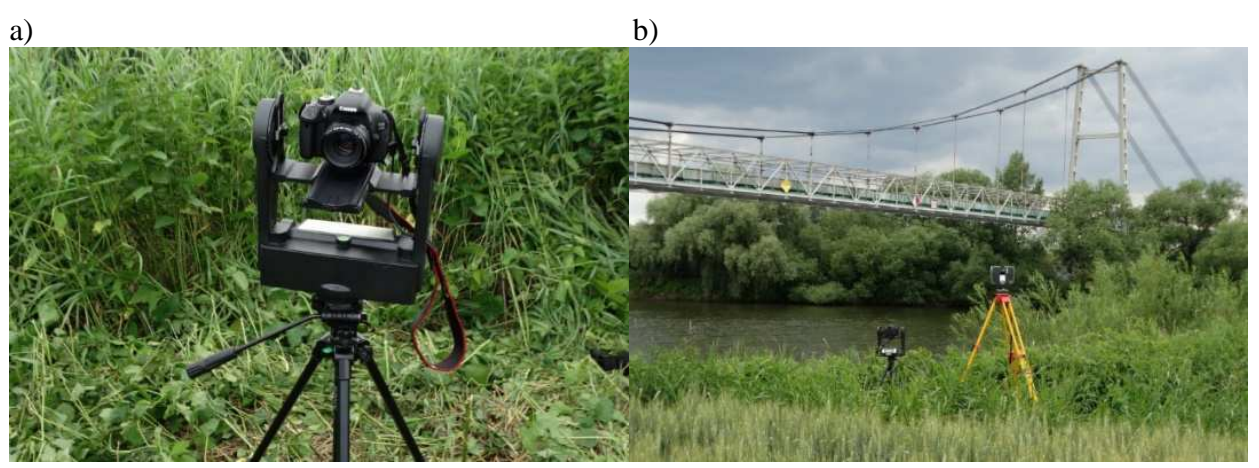

Rys. 4. Pomiary mostu z wykorzystaniem: a) kamery Canon 650D z obiektywem $85 \mathrm{~mm}$ i obrotnica GigaPano, b) skanera FARO Focus 3D X130

Fig. 4. Measurements of the bridge with using: a) Canon 650D camera with the lens $85 \mathrm{~mm}$ and GigaPano turntable, b) FARO Focus 3D X130 scanner

\subsection{Metoda skaningu laserowego}

Metoda skaningu laserowego to stosunkowo nowa metoda pomiarowa pozwalająca na uzyskanie quasi-ciągłej, przestrzennej reprezentacji powierzchni badanego obiektu. W wyniku pomiaru otrzymuje się przestrzenne chmury punktów powierzchni zewnętrznych obiektów widziane z pozycji skanera. Dokładność wyników uzależniona jest głównie od odległości skanera od badanego obiektu. W ostatnich kilku latach obserwuje się szybki rozwój skaningu laserowego [2, 3, 4].Skaner wykorzystuje promień laserowy, który po odbiciu od mierzonego obiektu wraca do skanera. Odległość jest wyznaczana na podstawie różnicy faz promienia wysłanego i odbitego. W trakcie pomiaru skaner może obracać się o 360 stopni w poziomie. Kąt poziomy i pionowy ustawienia lustra skanera oraz informacja o pomierzonej odległości są w czasie rzeczywistym przeliczane na współrzędne lokalne. Do badań mostu wykorzystano skaner FARO Focus 3DX130 (rys. 4b), który mierzy do $1 \mathrm{mln}$ punktów na sekundę i pozwala tworzyć chmury przekraczające miliard punktów. Deklarowana przez producenta dokładność pomiaru odległości wynosi $\pm 2 \mathrm{~mm}$, a rozdzielczość kątowa wynosi $0,009^{\circ}$ $(0,16$ miliradiana). Kolejne skany dopasowuje się do charakterystycznych punktów tak, aby kolejne sesje pomiarowe były spójne topologicznie [2].Pozwala to na znaczne skrócenie czasu pracy w terenie. Przy opracowaniu wyników okazało się, że w przypadku tego mostu, takie podejście nie jest właściwe. Jakość skanu mostu znajdowała się w górnej granicy zasięgu skanera, tj. 100-120 m. W trakcie analizy wyników okazało się, że jakość (gęstość punktów) skanu jest zbyt niska. W ramach testu sprawdzającego wykonano tym samym skanerem inwentaryzację zabytkowego (najstarszego w Europie) wiszącego mostu żeliwnego w Ozimku na rzece Mała Panew. Badania przeprowadzono przy znacznie mniejszych odległościach skanera od mostu, tj. $40 \mathrm{~m}$. Zarejestrowana gęstość chmury punktów pozwoliła na satysfakcjonującą identyfikację elementów (detali) mostu i w konsekwencji uzyskano w pełni zadowalające wyniki przemieszczeń mostu. 


\section{Wyniki badań i ich analiza}

Ogółem podczas pomiarów tachimetrycznych analizowano 10 punktów węzłowych (rys. 3a) na długości mostu i dwa pylony. Należy zwrócić uwagę, że pomiar tachimetryczny kilkunastu punktów pomiarowych jest rozciągnięty w czasie. Stąd najprawdopodobniej różnice w wartościach strzałek ugięcia są spowodowane brakiem pełnej synchronizacji czasowej pomiarów wykonywanych różnymi metodami. W analizie wyników nie podano rezultatów ze skaningu laserowego z powodu braku ich korelacji (zbyt duże różnice) z wynikami uzyskanymi innymi metodami. Jedną z bardziej istotnych przyczyn niepewnych wyników przemieszczeń uzyskanych za pomocą skaningu laserowego była zbyt duża odległość od mostu oraz to, że most wiszący ma konstrukcję ażurową, który wymaga skanów o większej gęstości niż uzyskane zastosowanym skanerem.

Wyniki przemieszczeń głównego przęsła mostu wiszącego dla wybranych trzech punktów pomiarowych $(1 / 4,1 / 2$ i 3/4 rozpiętości) zestawiono w Tabeli 1. Maksymalne wartości przemieszczeń nie przekraczają $72 \mathrm{~mm}$ dla metody tachimetrycznej i $60 \mathrm{~mm}$ dla metody fotogrametrycznej. Największe przemieszczenia mostu zostały zanotowane $\mathrm{w}$ środku rozpiętości mostu. Uzyskane maksymalne wartości przemieszczeń są znacznie mniejsze od wartości dopuszczalnej $(l / 500=330 \mathrm{~mm})$ zgodnie z normą PN-82/S-10052 [6] obliczonej jak dla stalowych mostów drogowych.

Na rys. 5 pokazano wybrane wyniki przemieszczeń mostu w 1/2 rozpiętości uzyskane metodą fotogrametryczną. Do pomiaru wybrano dobrze identyfikowalne punkty na konstrukcji mostu. Analiza uzyskanych wyników polegała na nałożeniu na siebie dwóch zdjęć. Pierwsze zdjęcie wykonano przy braku obciążenia - stojący taśmociąg bez urobku (rys. 5a), a drugie zdjęcie obrazuje nałożenie na siebie dwóch sekwencji zdjęć - bez obciążenia i w trakcie obciążenia eksploatacyjnego (rys. 5b). Na połączonych obrazach (rys. 5b)zwymiarowano jeden piksel do $10 \mathrm{~mm}$, a następnie policzono o ile pikseli są przesunięte względem siebie mierzone elementy. W efekcie w sposób dość dokładny określono zmianę ugięcia mostu pod wpływem działania obciążenia eksploatacyjnego taśmociąg $\mathrm{z}$ urobkiem (masa $\mathrm{w}$ przedziale $900-1100 \mathrm{Mg} / \mathrm{h}$ ) poruszający się $\mathrm{z}$ prędkością $2 \mathrm{~m} / \mathrm{s}$. W wyniku przeprowadzonych pomiarów, przemieszczenia mostu uzyskane przy zastosowaniu metody fotogrametrycznej są w granicach 16-27\% mniejsze niż te uzyskane za pomocą metody tachimetrycznej.

Tabela 1. Porównanie maksymalnych zarejestrowanych przemieszczeń mostu

Table 1. Comparison of the maximum registered displacements of the bridge

\begin{tabular}{|c|c|c|c|c|}
\hline Lp. & Metoda pomiaru & $\begin{array}{c}1 / 4 \text { rozpiętości } \\
(\mathrm{mm})\end{array}$ & $\begin{array}{c}1 / 2 \text { rozpiętości } \\
(\mathrm{mm})\end{array}$ & $\begin{array}{c}3 / 4 \text { rozpiętości } \\
(\mathrm{mm})\end{array}$ \\
\hline 1. & Tachimetryczna & 49 & 72 & 41 \\
\hline 2. & Fotogrametryczna & 40 & 60 & 30 \\
\hline 3. & Skaning laserowy & $*$ & $*$ & $*$ \\
\hline
\end{tabular}

Uwaga: * uzyskane rezultaty metodą skaningu laserowego uznano jako niepewne. 


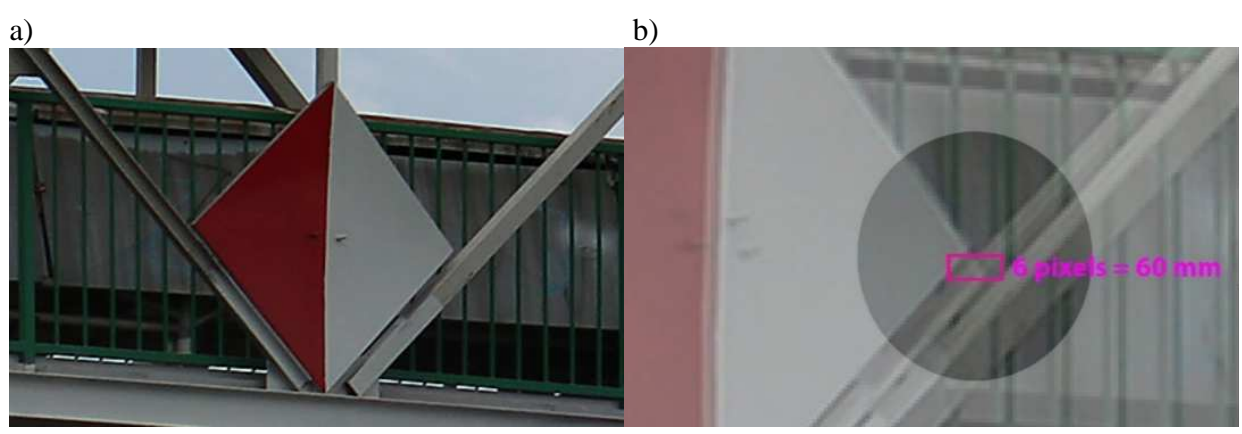

Rys. 5. Analizowany detal mostu w 1/2 rozpiętości przęsła: a) stan bez obciążenia, b) nałożenie dwóch sekwencji zdjęć (stan bez i z obciążeniem)

Fig. 5. The analysed detail in $1 / 2$ of the bridge span: a) without load, b) overlap of two sequences of photographs (without and with load)

\section{Wnioski}

W wyniku wykonanych pomiarów można wyciągnąć następujące wnioski:

1. Maksymalne przemieszczenia mostu uzyskane $\mathrm{z}$ metody tachimetrycznej zaobserwowano w środku rozpiętości i wynosiły $72 \mathrm{~mm}$. Największe przemieszczenia mostu należy uznać za stosunkowo niewielkie i w każdym przypadku były znacznie mniejsze od wartości dopuszczalnej. W oparciu o metodę fotogrametryczną uzyskano niedoszacowane wartości przemieszczeń mostu w stosunku do metody tachimetrycznej (16-27\%).

2. W metodzie fotogrametrycznej należy dobierać ogniskową kamery w taki sposób, aby wielkość piksela dla reprezentatywnej odległości była rzędu $2 \mathrm{~mm}$. Większa skala fotogramów pozwoli na uzyskiwanie dodatkowych danych o otoczeniu mierzonego punktu, np. trwałych deformacji, pęknięć, itp.

3. Metoda skaningu laserowego w przypadku tego mostu okazała się najmniej dokładna. Wynikało to z powodu zbyt dużej dla tego typu skanera odległości skanera od mostu i zbyt małej rozdzielczości skanera (gęstość punktów).

4. Aby metody tachimetryczna i fotogrametryczna spełniły stawiane wymagania dokładnościowe należałoby wykonać równoczesny pomiar kilkoma tachimetrami i kamerami tych samych punktów. W taki sposób uzyskano by odpowiednio dokładne informacje na temat przemieszczeń danego punktu pomiarowego. Takie podejście umożliwiłoby pełną synchronizację pomiarów, jednakże z praktycznego punktu widzenia takie pomiary są trudne do wykonania.

\section{Literatura}

[1] Berényi A., Lovas T., Barsi A., Dunai L.: Potential of terrestrial laserscanning in load test measurements of bridges. PeriodicaPolytechnica Civil Engineering, vol. 53, no. 1, 2009, pp. 25-33. 
[2] BeshrA.A.A.: Structural deformation monitoring and analysis of highway bridgeusing accurate geodetic techniques. Engineering, no. 7, 2015, pp. 488-498.

[3] Jauregui D.V., White K.R., Woodward C.B., Leitch K. R.: Noncontact photogrammetric measurement of vertical bridge deflection. Journal of Bridge Engineering, vol. 4, no. 4, 2003, pp. 212-222.

[4] Kwiatkowski J.L.: Monitorowanie budowlanych cykli realizacyjnych instalacji przemysłowych weryfikowane hybrydowymi technikami pomiarowymi. Praca doktorska, Politechnika Opolska Wydział Budownictwa i Architektury, Opole 2014.

[5] Luhmann T., Müller Ch.: Photogrammetrielaserscanningoptische 3D-messtechnik. Herbert WachmanVerlag, Heidelberg 2007.

[6] PN-82/S-10052. Obiekty mostowe. Konstrukcje stalowe. Projektowanie.

\section{ESTIMATION OF USEFULNESS OF GEODETIC MEASUREMENT METHODS TO TESTING OF THE SUSPENSION BRIDGE DISPLACEMENTS}

\section{S u m m a r y}

The objective of the study was to compare and assess suitability of three measurements methods,i.e.: tachymetry, photogrammetric, and laser scanning used to determine geometric changes of the structures. The methods were tested at the suspension technological bridge of $165 \mathrm{~m}$. Information on the change in the shape of bridge structure under the influence of service load are very significant concerning maintenance (exploitation). The scope of examinations included performing measurements of the changes in the bridge deflection values during the belt conveyor operation and stoppage. The tachymetry measurements were conducted using precise tachymetry(Leica TC2002). In the photogrammetric and laser scanning methods, a Canon 650D camera with high resolution and FARO Focus 3DX130 scanner were used, respectively. As a result of conducting the experimental tests, the obtained displacements' values of the main bridge span did not exceed $72 \mathrm{~mm}$, thus being lower than the limit values calculated in accordance with the bridge standard. The analysis of the obtained results of the laser scanning did not allow to estimate obtained displacements due to too long distance between the scanner and the bridge and too low density of scans.

Keywords: bridge, measurement, laser scanning, photogrammetry, tachymetry

Przestano do redakcji: 07.06.2016 $r$.

Przyjęto do druku: 30.06 .2016 r.

DOI: $10.7862 / \mathrm{rb} .2016 .45$ 